\title{
Improving blood safety and availability: a collective mindfulness perspective in the supply chain
}

\begin{abstract}
Purpose: Maintaining a safe and available supply of blood requires a mindfully coordinated supply chain (SC) and is fundamental to the effective operation of health systems across the world. This study investigates how blood supply chain (BSC) actors demonstrate collective mindfulness (CM) principles in their operations and how these demonstrations lead to improvements in blood safety and availability (BSA) in different operational contexts.

Design/methodology/approach: Six case studies drawn from two contrasting BSCs, the UK and Indonesia, which differ in structure and regulation are investigated in this research. Qualitative data are collected and analysed using template analysis.

Findings: The cases reveal how the CM principles are demonstrated in a range of operational conditions and their impact on BSA. The BSC actors in the more centralised and tightly regulated cases display more behaviours consistent with more of the $\mathrm{CM}$ principles over a greater range of operational conditions compared to those in the more decentralised and loosely regulated cases. As such, more improvements in BSA are found in the former compared to the latter cases.

Originality/value: This paper is considered the first to investigate the demonstration of $\mathrm{CM}$ principles at the SC as opposed to the single organisational level. It proposes an alternative approach to understanding and evaluating reliability performance using behavioural rather than statistical principles.
\end{abstract}

Keywords: Blood, safety and availability, system reliability, collective mindfulness, theory elaboration, template analysis

Paper type: Research paper 


\section{Introduction}

Blood is a precious resource, critical for the human body. It is also perishable; requiring a coordinated temperature-controlled supply chain (SC) to maintain high quality (see Turnbull, 1989; Van Donselaar et al., 2006). Reliable blood supply chain (BSC) operations are essential to ensure that blood products are always safe and available, saving lives whilst minimising wastage. Damaged blood units or those contaminated by infectious disease should never be transfused. Stock-outs of blood products delay transfusions and operations, directly affecting patients' lives, whilst outdated blood leads to wastage resulting in increased costs to the $\mathrm{SC}$ overall.

Given the criticality of blood products for human life, ensuring blood safety and availability (BSA) remains a perennial challenge (WHO, 2020). The degree to which BSA is achieved in the BSC essentially reflects the reliability of the healthcare system and is a key indicator of effective BSC management. Traditionally, a statistical approach has been used to measure system reliability, quantifying the number of failures as percentage of total relevant events (see Roberts, 1990). However, this has been criticised as being too rigid; some systems which frequently fail are still categorised as highly reliable because their success rate is much higher than their failure rate. As such, researchers argue that one should not only focus on failure and success rates, but more importantly understand the process by which organisations achieve system reliability (see Rochlin, 1993; Hopkins, 2007). In other words, more research should be focussed on identifying the processes and practices that help organisations achieve and maintain highly reliable operations (Hopkins, 2007).

Embracing this process driven orientation, Weick et al. (1999) argue that system reliability can be achieved through organisations being mindful of their operations. As such, people working together within highly reliable organisations are collectively mindful, following a wide range of processes and exhibiting a variety of behaviours that demonstrate their preoccupation with failure, reluctance to simplify interpretation, sensitivity to operations, commitment to resilience, and deference of decisions to those with expertise (Weick et al., 1999; Weick and Sutcliffe, 2007, 2015). It is argued that collective mindfulness (CM) manifests itself when there is interaction between individuals who carefully coordinate their actions (Vogus and Sutcliffe, 2012, Morgeson and Hofmann, 1999, Weick et al.,1999). By extension, CM is the work of paying attention to and making sense of available information distributed amongst members of an 
organisation (see Curtis et al., 2017), hence, mindful information sharing is fundamental in defining $\mathrm{CM}$.

At the SC level, information sharing often happens between the organisations which form the chain (Lusiantoro et al., 2018). In the BSC context, mindless interorganisational information sharing (IOIS) can lead to failure in BSC coordination, creating blood safety and availability incidents which are potentially fatal for patients (see SHOT, 2016, 2017, 2018). For example, a blood centre's failure to detect and share information with its associated hospital on the delivery of a wrong blood component caused serious harm in a patient receiving the wrong blood transfusion (SHOT, 2016). IOIS could therefore demonstrate the collective efforts of SC actors to mindfully manage and coordinate their interdependent operations, maintaining reliable performance and minimising failures (see Vogus and Sutcliffe, 2012; Weick et al., 1999).

Despite the important role of $\mathrm{CM}$ and its potential application in SC operations, empirical research linking $\mathrm{CM}$ and $\mathrm{SC}$ reliability from the process perspective is currently lacking. $\mathrm{CM}$ has most commonly been studied in the context of high reliability organisations (HROs) that deal with highly hazardous environments. Whilst Weick et al. (1999) suggest that $\mathrm{CM}$ could be used to understand reliability across inter-organisational networks and many theories have been used to study inter-organisational coordination (see Kembro et al., 2014), the extension of CM concept to the SC level is currently scant in the literature (see Sawyerr and Harrison, 2020). In addition, theoretical perspectives including CM have not been significantly used in the BSC literature which has focussed instead on quantitative rather than process and behavioural approaches to inventory optimisation, supply management, and scheduling the distribution of blood products to maintain blood safety and availability (see Beliën and Forcé, 2012; Pirabán et al., 2019), ignoring the potentially vital role of people in achieving reliability. Therefore, our understanding on how CM could influence blood safety and availability across the BSC remains absent.

To address this important research gap, in this research, we investigate CM in the BSC context using blood safety and availability as an exemplar of SC reliability performance. We seek to answer the following research question:

RQ: How does supply chain actors' collective mindfulness influence blood safety and availability? 
We specifically aim to investigate how BSC actors demonstrate CM principles through their IOIS behaviour and how these demonstrations could lead to improvements in blood safety and availability in different operational contexts. To achieve this aim, we investigate six cases of two BSCs with different structure and regulation (the UK and Indonesian cases). We find that the demonstrations of CM principles across the cases leads to improvements in blood safety and availability, and that the magnitude is different given the different structure and regulation of the BSCs.

The rest of the paper now proceeds as follows. We present a brief review of literature relevant to the study. We then describe our multiple case study methodology before presenting the findings, discussion, and finally concluding the paper.

\section{Literature Review}

Researchers have taken different approaches to understand the notion of system reliability. From industrial and manufacturing system contexts, Kirkmant (1963) as cited in Souza et al. (2020:134) first defines system reliability as the state of working or failed, that is "the probability that a technological system will operate correctly for a given period in a given environment". Whilst system reliability can help organisations make successful decisions, Souza et al. (2020) argue that current research in system reliability has focussed mostly on "local decisions", such as the health and productivity of an individual equipment, rather than the entire organisational processes. They emphasise that "in today's volatile and complex businesses, local decisions are no longer sufficient; it is necessary to analyze the organization entirely. Thus, being aware of the impacts that a local failure can impose on the entire company has significant weight in the decisionmaking process" (Souza et al. (2020:133).

From an organisational decision-making perspective, system reliability can stem from organisational routines that incorporate "repeatable packages of decision rules and associated actions" to reduce errors and variation in outcomes (Butler and Gray, 2006:214). "Routine-based reliability involves the creation and execution of standard operating and decision-making procedures" embedded in structured and standardised processes within an organisation (Spender, 1989 as cited in Butler and Gray, 2006:214). Kydd (1989) and Butler and Gray (2006), however, suggest that whilst structured processes and routines can significantly improve system reliability under stable conditions, they are not so effective under dynamic conditions that require adaptive decision-making approaches. 
On the other hand, Roberts (1990) defines system reliability in terms of achieving exceptional safety records that ultimately lead to what they classify as high reliability organisations (HROs). It is argued that "one can identify this subset [of organisations that have high safety records] by answering the question, "how many times could this organisation have failed resulting in catastrophic consequences that it did not? "If the answer is on the order of tens of thousands of times the organisation is "high reliability"', (Roberts, 1990:160). Rochlin (1993:17), however, argue that "what distinguishes reliability-enhancing organisations, is not their absolute error or accident rate, but their effective management of innately risky technologies through organisational control of both hazard and probability". Hopkins (2007:6) adds that "[the research] moves away from questions of just how safe does an organisation have to be before it can be considered an $\mathrm{HRO}$, and highlights instead what an organisation needs to do in order to reach the required end state". This advocates a process-oriented view of HROs as reliability-enhancing organisations, rather than a probabilistic approach to system reliability.

Reliability in an $\mathrm{HRO}$ requires a strong organisational safety culture, characterised by leadership commitment to safety, a shared belief in the importance of safety across the organisation, open communication based on trust, organisational learning, teamwork, and a non-punitive approach to adverse event reporting and analysis (Halligan and Zecevi, 2011). A cornerstone of safety culture is informed culture (Weick and Sutcliffe, 2007), defined by Goswami et al. (2009:6) as:

"[...] an organizational culture that encourages reporting of errors and near misses, a culture that is just in terms of apportioning error when things go wrong, a culture that is flexible enough to be able to adapt to sudden and radical increases in pressure, pacing and intensity of organizational operations, and a culture that enables members of the organization to use lessons learnt from past experiences to guide present operations and assumptions."

Informed culture encourages information sharing as a way to support collective organisational mindfulness, a notion that could serve as a complement to organisational routines operating in dynamic environments (Butler and Gray, 2006) and an important approach to understand how organisations achieve high reliability performance (Weick et al., 1999). 


\section{Collective mindfulness}

Collective mindfulness $(\mathrm{CM})$ developed from the Western perspective of individual mindfulness (see Weick et al., 1999). Instead of being based on meditation as in the Buddhist thought tradition of its Eastern counterpart, the Western perspective of individual mindfulness is defined more universally as "a flexible state of mind in which we are actively engaged in the present, noticing new things and sensitive to context" (Langer, 2000:220). "People act less mindfully when they rely on past categories, act on "automatic pilot," and fixate on a single perspective without awareness that things could be otherwise" (Weick and Putnam, 2006:280).

$\mathrm{CM}$ is more than the sum of each individual's mindfulness. It is a manifestation of the mindfully interacted behaviours carried out by the combined members of the organisation rather than the intrapsychic processes inside the head of each member of the organisation (Vogus and Sutcliffe, 2012, Butler and Gray, 2006). The practices of CM have most commonly been researched in studies of high reliability organisations (HROs) such as nuclear power plants, aircraft carriers, air traffic control systems, and healthcare operations, characterised by their ability to sustain almost "error-free" performance over long periods of time (Roberts, 1993; Sutcliffe, 2011). Researchers have also explored HRO theory in ordinary low hazard environments (Zohar and Luria, 2003) which also present a need for reliable operations, such as healthcare (Vogus and Sutcliffe, 2007a, b). In HROs, CM manifests as a dynamic social process, characterised by extensive, real-time information sharing reflecting the shared behaviours of the organisational members to manage their interdependent operations (Vogus and Sutcliffe, 2012). CM, through the lens of information sharing relates as much to the distribution of decisionmaking rights as it does to the capabilities of the individual (Butler and Gray, 2006). For example, as described in Kudesia (2019:418), "product engineers may receive information flows about an unexpectedly high number of broken products returned under warranty", however, if they do so with poorly structured information flows, they still will not be able to diagnose the problem correctly - proper information sharing will allow them to enact metacognitive processes allowing them to diagnose the problem.

In practice, collective mindfulness theory (CMT) is characterised as following the five core theoretical principles of mindful organising (Weick and Sutcliffe, 2007, 2015). At a collective level, demonstrating these principles contributes to the process of achieving reliable performance in an organisation, all of these can be linked to information sharing: 
1. Preoccupation with failure (PF). This principle relies on the sharing of information on failures, minor failures and near misses. Organisations which demonstrate this principle will thoroughly investigate near misses and incidents to understand the lessons learnt and procedures are frequently updated. People are rewarded for spotting errors and articulating potential mistakes. PF shows precaution, failure reporting, and openness (Weick et al., 1999; Weick and Sutcliffe, 2007, 2015; Lekka, 2011).

2. Reluctance to simplify (RS). Communication patterns and cognitive limitations lead to situations where unique information is not shared. Therefore, organisations demonstrating this principle keep redundant systems as back-ups. It is divergence not the commonalities which are key to detecting anomalies, scepticism and error spotting are encouraged to avoid making assumptions. RS also shows checks and balances (Ibid.).

3. Sensitivity to operations (SO). Organisations demonstrating this principle seek to understand the big picture of their operation through transparency as well as regular and real time interactions. Sharing information is crucial, combining multiple perspectives to build a collective story. They encourage speaking up, monitoring operations, and ongoing operational adjustments preventing errors from cumulating (Ibid.).

4. Commitment to resilience (CR). This principle embraces preparedness by developing the capacity to cope with unexpected events. Organisations quickly respond when unexpected events occur, rapidly pooling knowledge to handle events which were impossible to anticipate. Sets of contacts are quickly developed to help solve problems as they occur. CR also shows recovery and growth from disruptions (Ibid.).

5. Deference to expertise (DE). With this principle, when something out of ordinary happens, information is shared regardless of hierarchical rank. Recognising that expertise is not always held at the top of the organisation. Organisations embrace a flexible decision-making structure and encourage a collective rather than an authoritative decision-making process (Ibid.).

Through these five principles, collective knowledge of failures, potential for recovery and relevant past experience are mindfully processed, providing the context in which present 
operations make sense or can be reconstructed to make sense (Weick et al., 1999). Therefore, collective knowledge (i.e. shared information) is collective mindfulness and information sharing gives us a useful way of measuring it. Weick and Sutcliffe (2007) further classify these CM principles according to when they are demonstrated. PF, RS, and $\mathrm{SO}$ are categorised as the principles of anticipation which are typically demonstrated under normal conditions (i.e. when there are no unexpected events interrupting operations), whereas $\mathrm{CR}$ and DE are typically seen once unexpected events occur. For example, when a wildfire blows out of control and becomes catastrophic, CR and DE are demonstrated to contain the impact. $\mathrm{CR}$ and DE are categorised as the principles of containment which are commonly identified in emergency conditions.

\section{Collective mindfulness and the blood supply chain}

The BSC requires operations which are always reliable. Perishability of blood products and uncertainty in both demand and supply makes the BSC complex, requiring operations which run to exacting standards (Beliën and Forcé, 2012). Blood products must be held in temperature-controlled facilities and stored and transported in compliance with stringent safety and quality regulations. A series of continuous logistical processes are required, connecting the donor to the patient, ensuring demand is satisfied in a timely manner regardless of the operating conditions, conscious that failure to provide safe blood can ultimately lead to a patients' death. As such, appropriate coordination mechanisms including IOIS (see Li and Wang, 2007) are required to synchronise activities across the BSC (WHO, 2020).

Despite the requirement for high levels of reliability in the BSC, there is no research which we are aware of which uses the principles of CM to understand reliability in the BSC context, the extant literature in this area has focussed more on using mathematical model and optimisation to study reliability (e.g. Diabat et al., 2019; Rahmani, 2019; Samani and Hosseini-Motlagh, 2019). However, a considerable amount of research has adopted the idea of CM in the more general healthcare context. For example, Vogus and Sutcliffe (2007a, b), and Vogus et al. (2010) use the five core CM principles to explore safety practices in healthcare providers. Their research shows that $\mathrm{CM}$ enables people in healthcare organisations to communicate safety problems, reduce errors, and to elaborate learning from failures resulting from their actions (Vogus et al., 2010). As such, the demonstrations of $\mathrm{CM}$ principles have been associated with both lower medication errors and patient falls in hospitals (Vogus and Sutcliffe, 2007a). 
Despite the extant applications of $\mathrm{CM}$ in the general healthcare operations, they are only studied in a single organisational rather than supply chain context, where catastrophic events can potentially happen, particularly when IOIS is difficult to achieve and the complex system is hard to comprehend (Turner, 1976; Weick et al., 1999). In addition, the most recent systematic review of the BSC literature shows a lack of theoretical perspectives used to understand the BSC phenomenon (see Pirabán et al., 2019). Most of the reviewed studies are quantitative (operations research) papers, overlooking the pivotal role of people (see Stanger et al., 2012) and the coordination mechanisms that could potentially give us a better understanding of the BSC actors' CM and its influence on blood safety and availability. Our research fills this gap. We investigate the extent to which CM principles are demonstrated through IOIS behaviours and explain how the demonstrations of CM principles could lead to BSA improvements in normal, high tempo, and emergency conditions. Figure 1 illustrates the initial theoretical framework developed for the purpose of this research.

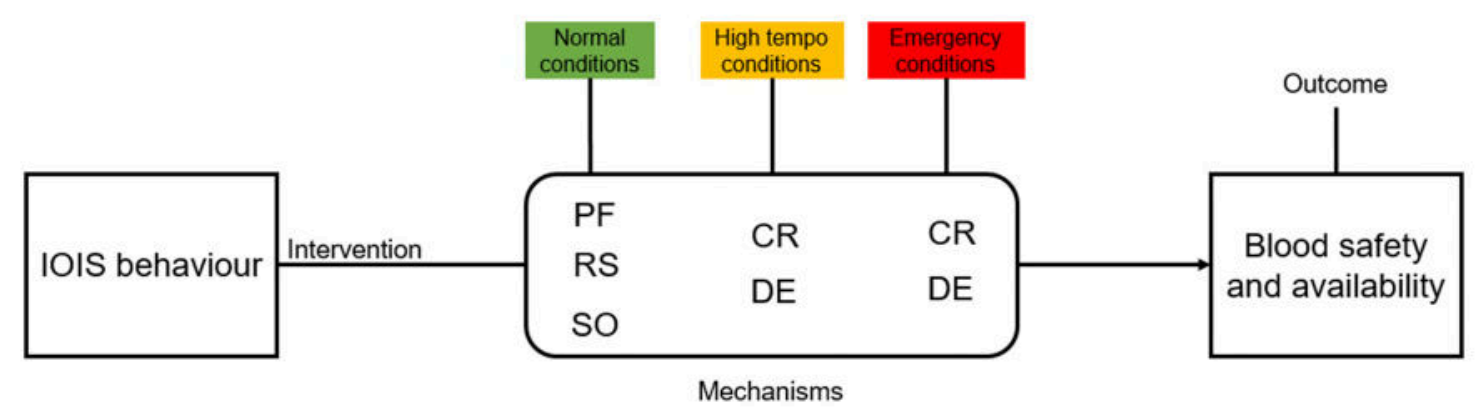

Figure 1. Initial theoretical framework of collective mindfulness in the blood supply chain

\section{Methodology}

We use a theory-elaborating case study (Ketokivi, 2006; Ketoviki and Choi, 2014), applying Collective Mindfulness Theory (CMT) to the context of the BSC. To achieve the study objectives, we use an abductive strategy, going back and forth between the theory and the empirical data (Ketokivi and Choi, 2014) to determine plausible explanations for the phenomenon (see Harman, 1965; Ketokivi, 2006; Merton, 1957). 


\section{Case selection and description}

To ensure the richness and accuracy of the research (see Martin and Eisenhardt, 2010; Yin, 2003), we select six cases from two contrasting contexts, distinct in regulation and centralisation; the UK BSC - Context 1 and the Indonesian BSC - Context 2. Governmental approaches to funding and managing healthcare vary across the world. The approach to funding has a direct influence on how healthcare supply chains, including those supplying blood are structured and regulated. Four primary approaches exist, and the two contexts included in this study follow radically different approaches, fundamentally impacting on how the supply chains operate (Dobrzykowski, 2019). Healthcare in the UK follows the Beveridge model, with a centralised National Health Service funded exclusively by the government. National Health Service Blood and Transplant (NHSBT) is part of this centralised system and is solely responsible for managing all blood supply processes including blood collection, testing, manufacturing, stock holding, and distribution of blood across the UK. In addition, BSA in the UK is governed by tight national regulations under the Medicines and Healthcare products Regulatory Agency (MHRA). The regulations cover many issues including minimum national stock levels, traceability of blood products, and mandatory reporting of blood safety incidents.

In contrast, the Indonesian healthcare system is made up of a mixture of public and private organisations and funding with a decentralised public system administered in line with the government system in Indonesia. The blood supply chain mainly sits in the charitable sector, managed on a decentralised basis by the Indonesian Red Cross (Palang Merah Indonesia-PMI). Each of 414 blood centres (Ministry of Health Republic of Indonesia, 2017, 2018) is individually responsible for collecting, manufacturing, holding stock, and distributing blood and blood products to hospitals within its operational area. National regulation of standards for blood transfusion do exist covering processes such as blood quality management, blood donation, and cold chain process. However, the regulations are not comprehensive with some governance aspects, such as national guidelines on the appropriate clinical use of blood and a national haemovigilance system lacking (WHO, 2017). Effective national or local systems are not in place to assist BSC operators in complying with the regulations and as a consequence not all BSC actors follow the prescribed standard (Director of National Blood Donation and Hospital of the Indonesian Red Cross, interview data). 
The differences in funding, structure, and regulation of our contrasting contexts will allow our cases to provide an interesting, rich, and comprehensive understanding of the $\mathrm{CM}$ phenomenon demonstrated through IOIS, increasing the theoretical generalisability of the research. Theoretically, Weick et al. postulate that some degree of centralisation is required to support the demonstration of $\mathrm{CM}$ principles potentially in a supply chain context (see Weick et al., 1999; Weick and Sutcliffe, 2007). Additionally, regulation provides a way to establish measures, rules, procedures or guidelines leading to higher reliability operations (La Porte and Thomas, 1995; Lekka, 2011). There is however, a danger that strict regulation will encourage routine based rather than mindfulness-based reliability leading to mindless actions, which hinder the mindful detection of unexpected changes in the organisation's environment (Butler and Gray, 2006; Kutsch et al., 2013; Sitkin et al., 1994; Weick et al., 1999). In fact, WHO (2020) recommends that nationally integrated and regulated blood supply networks are required to ensure BSA.

Each case consists of one blood centre and four associated hospitals, giving a total of 30 participating entities. The number of cases selected is in line with Eisenhardt's (1989a) suggestion that the ideal number of cases is between four and ten. Table 1 provides details of the selected cases from both BSC contexts. To maintain confidentiality, the names of the blood centres $(\mathrm{BC})$ and the hospitals are coded.

The cases were selected using a convenience approach (see Aggarwal and Srivastava, 2016; Pagell and Krause, 1999). The three blood centres and their associated hospitals in the UK were chosen based on the recommendation of the National Health Service Blood and Transplant (NHSBT) Blood Stocks Management Scheme (BSMS) Manager. Similarly, the three blood centres in Indonesia were selected following discussion with the Director of National Blood Donation and Hospitals of the Indonesian Red Cross (PMI). Given the decentralised structure of the Indonesian BSC, the selection of the four hospitals associated with each blood centre was based on the recommendation of the blood centre manager. The selection of the cases considered the different sizes, locations, and blood inventory management practices of the entities. This variety ensures the validity and rigour of the cases, reduces bias in the data (see Stanger, 2013) and enables the identification of as many different IOIS behaviours and hence CM principles as possible. 
Table 1: Profile and data description of the selected cases in each study context

\begin{tabular}{|c|c|c|c|c|c|}
\hline Contexts & Cases & Entities & $\begin{array}{l}\text { Total } \\
\text { hospitals } \\
\text { served by } \\
\text { the BCs }\end{array}$ & Hospital types & Respondents \\
\hline \multirow{20}{*}{$\begin{array}{l}\text { More } \\
\text { centralised } \\
\text { \& tightly } \\
\text { regulated } \\
\text { BSC } \\
\text { (Context-1) }\end{array}$} & & Central & Over 250 & - & Head of Hospital Customer Service \\
\hline & & NHSBT & & & National Lead Patient Blood Management \\
\hline & & & & & Practitioner Team \\
\hline & & & & & National Product Manager \\
\hline & & & & & Assistant Director Governance and Resilience \\
\hline & Case 1-1 & BC 1-1 & 49 & - & Hospital Services Team Manager \\
\hline & & SG Hospital & - & University Teaching Hospital & $\begin{array}{l}\text { Lead Transfusion Practitioner, Transfusion } \\
\text { Practitioner }\end{array}$ \\
\hline & & FP Hospital & - & General Hospital & $\begin{array}{l}\text { Lead Transfusion Practitioner, Transfusion } \\
\text { practitioner, Biomedical Scientist }\end{array}$ \\
\hline & & W Hospital & - & $\begin{array}{l}\text { General or District General } \\
\text { Hospital }\end{array}$ & $\begin{array}{l}\text { Chief Biomedical Scientist the Transfusion } \\
\text { Manager }\end{array}$ \\
\hline & & WH Hospital & - & District General Hospital & $\begin{array}{l}\text { Blood Transfusion Coordinator and Quality } \\
\text { Lead,, Associate Practitioner, Biomedical } \\
\text { Scientist }\end{array}$ \\
\hline & Case 1-2 & $\mathrm{BC} 1-2$ & 13 & - & Hospital Services Manager \\
\hline & & JR Hospital & - & University Teaching Hospital & $\begin{array}{l}\text { Laboratory Manager, Transfusion Practitioner, } \\
\text { Project Development Manager }\end{array}$ \\
\hline & & WP Hospital & - & $\begin{array}{l}\text { General or District General } \\
\text { Hospital }\end{array}$ & $\begin{array}{l}\text { Transfusion Practitioner, Senior Biomedical } \\
\text { Scientist }\end{array}$ \\
\hline & & NG Hospital & - & $\begin{array}{l}\text { General or District General } \\
\text { Hospital }\end{array}$ & $\begin{array}{l}\text { Operational Manager Transfusion and } \\
\text { Haematology }\end{array}$ \\
\hline & & SM Hospital & - & $\begin{array}{l}\text { General or District General } \\
\text { Hospital }\end{array}$ & Lead Biomedical Scientist \\
\hline & Case 1-3 & BC 1-3 & 15 & - & Hospital Services Manager \\
\hline & & RB Hospital & - & $\begin{array}{l}\text { General or District General } \\
\text { Hospital }\end{array}$ & $\begin{array}{l}\text { Transfusion Head Biomedical Scientist and } \\
\text { Clinical Transfusion Services Manager }\end{array}$ \\
\hline & & SHG Hospital & - & University Teaching Hospital & Blood Transfusion Section Manager \\
\hline & & QA Hospital & - & General Hospital & $\begin{array}{l}\text { Blood Transfusion Operations Manager, BMS } \\
\text { Section Leader }\end{array}$ \\
\hline & & BNH Hospital & - & District General Hospital & $\begin{array}{l}\text { Transfusion Operations Manager, Senior } \\
\text { Biomedical Scientist }\end{array}$ \\
\hline \multirow{6}{*}{$\begin{array}{l}\text { More } \\
\text { decentralise } \\
\text { d \& loosely } \\
\text { regulated } \\
\text { BSC } \\
\text { (Context-2) }\end{array}$} & & Central PMI & 2,869 & - & Director of National Blood Donation and Hospital \\
\hline & Case 2-1 & BC 2-1 & 75 & - & $\begin{array}{l}\text { Blood Donation and Marketing Manager, Blood } \\
\text { Storage and Distribution Manager, Project } \\
\text { Development Manager, Staff of Blood Testing } \\
\text { Department, Quality Control Manager }\end{array}$ \\
\hline & & $\begin{array}{l}\text { PMU } \\
\text { Hospital }\end{array}$ & - & General Hospital & Laboratory Manager, Transfusion Practitioner \\
\hline & & KI Hospital & - & General Hospital & Laboratory Manager, Blood Bank Manager \\
\hline & & HM Hospital & - & General Hospital & Medical Consultant, Laboratory Manager \\
\hline & & PW Hospital & - & General Hospital & Laboratory Manager \\
\hline
\end{tabular}




\begin{tabular}{|c|c|c|c|c|c|}
\hline Contexts & Cases & Entities & $\begin{array}{l}\text { Total } \\
\text { hospitals } \\
\text { served by } \\
\text { the BCs }\end{array}$ & Hospital types & Respondents \\
\hline & \multirow[t]{5}{*}{ Case 2-2 } & BC 2-2 & 150 & - & $\begin{array}{l}\text { Head of City Red Cross, Blood Donation } \\
\text { Manager, Blood Management General Affairs }\end{array}$ \\
\hline & & PR Hospital & - & General Hospital & Deputy Laboratory Manager \\
\hline & & BT Hospital & - & General Hospital & Blood Bank Staff \\
\hline & & AK Hospital & - & General Hospital & Blood Bank Manager, Blood Bank Staff \\
\hline & & SD Hospital & - & Mother and Children Hospital & Midwife \\
\hline & \multirow[t]{5}{*}{ Case 2-3 } & BC 2-3 & 7 & - & Transfusion Practitioner \\
\hline & & MD Hospital & - & General Hospital & Senior Nurse, Nurse \\
\hline & & TR Hospital & - & General Hospital & $\begin{array}{l}\text { Hospital General Affairs, Blood Administration } \\
\text { Manager }\end{array}$ \\
\hline & & IS Hospital & - & General Hospital & Two nurses \\
\hline & & PMA Hospital & - & General Hospital & Nurse \\
\hline
\end{tabular}

\section{Data collection}

Primary data were collected through face-to-face semi-structured interviews (INTs) with the key personnel responsible for ensuring BSA in their respective blood centres or hospitals. In total 58 respondents were interviewed ( 29 UK and 29 Indonesian). The length of the interviews varied between 30 minutes to 2.5 hours. The interviews began with general questions on the respondents' role and the extent to which they were involved in managing BSA in the blood centre or hospital. Subsequently, the respondents were asked to describe how they (representing the blood centre or hospital) used IOIS to ensure BSA in normal, high tempo, and emergency conditions as the theory predicts that collective mindfulness principles will be demonstrated differently under differing operational conditions. We asked detailed questions as to what, how, with whom, and how often information is shared across the BSC.

Normal conditions represent business as usual operations where there are no particular events that might significantly affect blood safety and availability (BSA). High tempo conditions are those where events occur which cause sudden changes in BSA. These conditions include internal events (e.g. blood safety incidents, blood shortage, local stockouts, overstocks) and external events (e.g. Christmas, Easter, Bank Holiday, Olympic Games) that cause "turbulence" (i.e. manageable changes or fluctuations in BSA) within the BSC. High tempo events may be unexpected, anticipated, or cyclical in nature. Finally, major unexpected events, such as major haemorrhages, major traffic accidents, fridge failures, floods, terrorist attacks, cyber-attacks, national stock-outs, and any other unexpected events causing high levels of disruption within the BSC, are categorised as emergency conditions. 
Following the interviews, walkthroughs (WTs) in the form of blood centre and laboratory tours were conducted to understand how operationally IOIS ensured BSA. The walkthroughs lasted between 30 minutes and one hour and were tape-recorded. Supporting documents (DCMTs), artefacts (ARTFs) and/or archives (ARs) were also collected when applicable. This triangulation of data sources helped to ensure the accuracy of the data and the credibility and robustness of the research (Jick, 1979; Martin and Eisenhardt, 2010; Rothbauer, 2008). The data collection protocol was initially pilot tested with seven BSC practitioners ( 3 from the UK and 4 from Indonesia) to ensure that the respondents would understand the questions and to prevent misinterpretation that could lead to biased results.

\section{Data analysis}

All interviews were transcribed, coded, and analysed using template analysis, a thematic data analysis technique which allows flexibility of coding structure, defining tentative a priori themes, and an iterative process for applying, modifying, and re-applying the initial template (King, 2012). This technique is suitable for studying the underlying mechanisms of a relationship between constructs (see Lusiantoro et al., 2018) and allows the elaboration of a priori concepts in the coding process.

In the first stage of the coding process, we focussed on investigating how the CM principles were demonstrated through information sharing between blood centres and their associated hospitals. Blood centres supply blood to meet demand in hospitals, this direct relationship makes them the most important participants in the BSC. As such, we use the term "BSC actors" to refer to blood centres and hospitals throughout this paper. In this study, we assess $\mathrm{CM}$ as the extent to which the IOIS behaviours and practices observed demonstrate the five $\mathrm{CM}$ principles discussed in the literature review section. The more principles demonstrated through IOIS, the more collectively mindful is the BSC case. To do this, we conducted explanation building (Yin, 2014) via the following coding process:

1. First order coding identified excerpts specifically related to IOIS from the transcripts using an in vivo technique, where labels were assigned to the excerpts using words or short phrases taken from the excerpts themselves (King, 2008).

2. The IOIS behaviour amongst the BSC actors was categorised in terms of content, modality, direction, and frequency of IOIS (see Kembro and Näslund, 2014; see also Mohr and Nevin, 1990) in normal, high tempo, and emergency conditions.

3. The co-actions underpinning the IOIS behaviours (i.e. what the BSC actors were really trying to do with the IOIS) were matched with the a priori themes, the detailed elements 
of CM principles derived from a comprehensive review of current thinking on CM (i.e. Weick and Sutcliffe, 2007, 2015; Weick et al., 1999; Lekka, 2011).

The second stage of the coding process interpreted the impact of demonstrating each element of CM on BSA. As such, we used an inductive approach and the results are indicative rather than exact measures of the impacts. We then grouped the impacts into different categories of changes in BSA conditions before and after information is shared. In line with WHO (2020) and Serious Hazards of Transfusion (SHOT) (2016), blood safety covers issues, such as virus contamination, patient reaction to transfusion, blood quality, and safety-related issues/incidents, both in blood centres and their associated hospitals. Blood availability refers to blood stock levels or sufficiency both in blood centres and their associated hospitals. Measures such as stockout, overstock, and wastage are also included within blood availability. Table 2 illustrates how the coding was structured around contexts, interventions, mechanisms, and outcomes to answer the research question.

\section{Within-case and cross-case analyses}

Upon completion of the template analysis, within-case analysis was conducted by examining the demonstrations of the CM principles for each operational condition (i.e. in normal, high tempo, or emergency) for each case in each context. Cross-case analysis was then conducted to compare and contrast the $\mathrm{CM}$ principles identified in the cases across the two contexts. Within-case analysis identified the patterns of data within each case to understand the studied phenomenon from the perspective of a stand-alone entity (Voss et al., 2002). Whereas, crosscase analysis sought to identify replication of the findings across cases (Bourgeois and Eisenhardt, 1988; Eisenhardt, 1989a, 1989b; Martin and Eisenhardt, 2010; Voss et al., 2002; Yin, 2014). The ultimate aim of these analyses is "to build a general explanation that fits each individual case, even though the cases will vary in their details" (Yin, 2014:148). The process for conducting within-case and cross-case analyses in this research was adapted from Bourgeois and Eisenhardt (1988) and Martin and Eisenhardt (2010), who have provided clear practical guidance on the notion of replication logic. 
Table 2: Examples of template analysis coding

\begin{tabular}{|c|c|c|c|c|c|c|c|c|}
\hline \multirow{2}{*}{$\begin{array}{l}\text { Contexts } \\
\begin{array}{l}\text { Operational } \\
\text { conditions }\end{array}\end{array}$} & \multirow[b]{2}{*}{\begin{tabular}{l}
\multicolumn{1}{c}{ Interventions } \\
IOIS behaviour - \\
content; modality; \\
direction; frequency
\end{tabular}} & \multicolumn{3}{|c|}{ Mechanisms } & \multicolumn{2}{|c|}{ Outcomes } & \multirow[b]{2}{*}{ Representative excerpts } & \multirow[b]{2}{*}{$\begin{array}{l}\text { Supporting } \\
\text { entities } \\
\text { (sources of } \\
\text { evidences and } \\
\text { total number of } \\
\text { excerpts) }\end{array}$} \\
\hline & & $\begin{array}{l}\text { Co-actions (first- } \\
\text { order codes) }\end{array}$ & $\begin{array}{l}\text { Classified co- } \\
\text { actions into } \\
\text { elements of } \\
\text { CM principles } \\
\text { (second-order } \\
\text { codes) }\end{array}$ & $\begin{array}{l}\text { CM } \\
\text { principles }\end{array}$ & $\begin{array}{l}\text { Impacts on BSA } \\
\text { (entities affected) } \\
\text { (first-order } \\
\text { codes) }\end{array}$ & $\begin{array}{l}\text { Classified } \\
\text { impacts on } \\
\text { BSA (second- } \\
\text { order codes) }\end{array}$ & & \\
\hline Normal & $\begin{array}{l}\text { Weak signal of blood } \\
\text { quality problem; } \\
\text { telephone; } \\
\text { hospital } \rightarrow \text { blood } \\
\text { centre; ad hoc }\end{array}$ & $\begin{array}{l}\text { Being precautious of } \\
\text { the weak signal of } \\
\text { blood quality } \\
\text { problem }\end{array}$ & Precaution & PF & $\begin{array}{l}\text { Prevented usage } \\
\text { of blood with the } \\
\text { potential quality } \\
\text { problem }(\mathrm{H})\end{array}$ & $\begin{array}{l}\text { Assurance of } \\
\text { BSA (blood } \\
\text { quality) }\end{array}$ & $\begin{array}{l}\text { "Sometimes people just don't like the look of } \\
\text { something. And you know if you don't like the } \\
\text { look of a product, people phone up and say } \\
\text { you know I don't like the look of the product. } \\
\text { But it's not often that we get a quality } \\
\text { problem." INT - Blood Transfusion } \\
\text { Coordinator and Quality Lead WH Hospital } \\
\text { Case 1-1 }\end{array}$ & $\begin{array}{l}\text { WH Hospital } \\
\text { (INT 1, WT 1) }\end{array}$ \\
\hline High tempo & $\begin{array}{l}\text { Blood shortage and } \\
\text { product substitution; } \\
\text { fax and email; blood } \\
\text { centre } \rightarrow \text { hospital; ad } \\
\text { hoc }\end{array}$ & $\begin{array}{l}\text { Using redundant } \\
\text { information sharing } \\
\text { media }\end{array}$ & Redundancy & RS & $\begin{array}{l}\text { Ensured } \\
\text { awareness of } \\
\text { blood shortage } \\
\text { and substitution } \\
\text { (H) }\end{array}$ & $\begin{array}{l}\text { Potential } \\
\text { adjustment of } \\
\text { operations } \\
\text { towards BSA } \\
\text { (blood } \\
\text { shortage) }\end{array}$ & $\begin{array}{l}\text { "So generally we will get a fax and an email } \\
\text { to say that there is a shortage of the blood } \\
\text { component and we are advised to use } \\
\text { substitutions." INT - Transfusion Practitioner } \\
\text { SG Hospital Case 1-1 }\end{array}$ & $\begin{array}{l}\text { BC 1-1 (INT 4), } \\
\text { W Hospital } \\
\text { (INT 3), SG } \\
\text { Hospital (INT } \\
\text { 3), FP Hospital } \\
\text { (INT 2) }\end{array}$ \\
\hline Emergency & $\begin{array}{l}\text { Order information; } \\
\text { OBOS and telephone; } \\
\text { hospital } \rightarrow \text { blood } \\
\text { centre; ad hoc }\end{array}$ & $\begin{array}{l}\text { Being responsive in } \\
\text { addressing the } \\
\text { immediate need for } \\
\text { blood during } \\
\text { emergency; } \\
\text { authorising the } \\
\text { shared information; } \\
\text { using redundant } \\
\text { information sharing } \\
\text { media }\end{array}$ & $\begin{array}{l}\text { Responsive- } \\
\text { ness; } \\
\text { scepticism; } \\
\text { redundancy }\end{array}$ & CR; RS & $\begin{array}{l}\text { Ensured } \\
\text { awareness of } \\
\text { incoming order } \\
\text { during } \\
\text { emergency }(\mathrm{BC}) \text {; } \\
\text { confirmed order } \\
\text { during } \\
\text { emergency }(\mathrm{H})\end{array}$ & $\begin{array}{l}\text { Potential } \\
\text { adjustment of } \\
\text { operations } \\
\text { towards BSA; } \\
\text { assurance of } \\
\text { BSA (stock } \\
\text { availability) }\end{array}$ & $\begin{array}{l}\text { "So if the patient is O neg and they are } \\
\text { bleeding very heavily, then we probably } \\
\text { would need to get some blood down very } \\
\text { quickly for them. If they are O pos, we've } \\
\text { probably get plenty of stock to support them } \\
\text { until [they get what they need] and then we } \\
\text { may need to get some more afterwards. If } \\
\text { someone's [condition is] very complicated or } \\
\text { they are going to [use up] our stock like } \\
\text { nobody's business, then we would order blue } \\
\text { light from NHSBT. And you have to have } \\
\text { consultant, named consultant to authorise a } \\
\text { blue light delivery. And it's very clear on the } \\
\text { OBOS, you can click blue light, you have to } \\
\text { put all those details in and then you click } \\
\text { send and then you follow it up with phone } \\
\text { call, just to let them know that it's coming } \\
\text { through." INT- Transfusion Practitioner FP } \\
\text { Hospital Case 1-1 }\end{array}$ & $\begin{array}{l}\text { BC 1-1 (WT 1; } \\
\text { DCMT 1), SG } \\
\text { Hospital (WT } \\
\text { 2), FP Hospital } \\
\text { (INT 1), W } \\
\text { Hospital (INT } \\
\text { 1) }\end{array}$ \\
\hline
\end{tabular}




\section{Findings}

This section outlines the main findings of this research. The first part describes the demonstration of the CM principles, and the second part explains how demonstration of the $\mathrm{CM}$ principles leads to improvements in blood safety and availability.

\section{Demonstration of the $\mathrm{CM}$ principles}

Our findings show that the CM principles are demonstrated across a range of operational conditions in both contexts. The following subsections describe this in more detail.

\section{Preoccupation with failure (PF)}

Our findings show that BSC actors demonstrate their preoccupation with failure through the IOIS behaviours of precaution and failure reporting, in normal and high tempo conditions across all cases in Context-1 and Case 2-1 in Context-2.

For example, showing precaution, under normal conditions, WH Hospital in Case 1-1 shares information on weak signals of failure or blood quality issues (e.g. a strange look or colour to the blood) with Blood Centre BC 1-1, preventing unwanted consequences for patients such as blood safety incidents. The hospital does not wait until it is certain that there are blood quality issues before reporting to the blood centre.

Failure reporting is displayed when Hospitals RB and WH in Cases 1-3 and 1-1 report blood safety incidents (e.g. severe reactions to transfusion or bacterially contaminated units) to their Blood Centre. This reporting is crucial as a single donation is often split into a number of products which can be delivered to different hospitals. These hospitals are not only demonstrating resilience by immediately reporting incidents to the blood centre, but are also being cautious, endeavouring to prevent incidents in other hospitals caused by using blood products coming from the same donation. The Blood Transfusion Coordinator and Quality Lead at WH Hospital describes:

"If we think that it looks like bacterially contaminated units, we would be talking to NHSBT and highlighting that. And if we had a particularly nasty reaction, we would phone NHSBT up anyway. Because more than one product is made from the one donation and we've had particularly nasty reactions, often NHSBT would then recall all the other products just to be safe." INT - Blood Transfusion Coordinator and Quality Lead WH Hospital Case 1-1

Additionally, all hospitals in Context-1 report failures via a national incident reporting system. This system is used to generate annual lessons learnt reports which help BSC actors identify 
errors and improve their BSA. The reported failures include but are not limited to delays in transfusion, incorrect labels, incorrect transfusion, and incorrect cross-match.

In Context-2, PMU Hospital demonstrates precaution when they share their blood donation plan with Blood Centre 2-1 to prevent blood stockouts. In addition, KI Hospital reports recurrent blood quality issues to Blood Centre 2-1 so that the cause can be traced at source. As the Laboratory Manager in Hospital KI describes:

"If for example there is a complaint from the ward, "why are there often clots in the blood?". We receive the complaint and phone the blood centre, "why are there always clots in the blood? It's difficult to transfuse to patients"." INT - Laboratory Manager KI Hospital Case 2-1

\section{Reluctance to simplify (RS)}

Our findings show that BSC actors demonstrate their reluctance to simplify their actions and processes through the IOIS behaviours of redundancy, scepticism, and checks and balances in both normal and high tempo conditions in all cases and in emergency conditions in Context1. Under normal conditions, BSC actors in all cases employ redundancy, when they ensure that BSA related information is received and understood by employing multiple information sharing mediums (e.g. combining meetings, website, and email or combining order form and telephone to convey the same message). Sceptical of other actors actions, they create systems which do not presuppose that the precautions are sufficient, continuously questioning and confirming their actions through information sharing.

For example, in Case 1-2 the blood centre questions unexplained orders for fresh blood (high remaining shelf life) from hospitals, ensuring that requests are made for justified clinical purposes. This avoids unnecessary use of fresh blood for transfusion, which can lead to overstocking and wastage. As Hospital Services Manager in Blood Centre BC 1-2 reports:

"If we notice that something is out of the ordinary that they have ordered, we might question and say "did you want to speak with the clinician?", we might question it if they order really out of ordinary." INT - Hospital Services Manager BC 1-2 Case 1-2

In Context-2, several hospitals do not have their own blood banks. When these hospitals order blood, they effectively reserve the blood units in the blood centre's cold store. To ensure that the ordered blood is not wasted, the blood centre will regularly question whether the ordered blood is still required by the hospital. The following respondent illustrates this:

"When the patient has gone home, there is then a decision that the blood is not used. It can be that the blood centre phones us or we phone the blood centre to cancel the [ordered and reserved] blood, [because] it's not going to be used." INT - Midwife SD Hospital Case 2-2. 
In high tempo conditions, such as when a blood product is recalled, blood centres in Context1 cases are sceptical, requiring written evidence from the hospital documenting that the unit has been withdrawn from stock. Further, to ensure blood availability during the Christmas period, blood centres employ checks and balances by sharing their updated blood inventory policies with the hospitals. Requiring that hospitals clinically justify orders for fresh blood during this time. As the following excerpt suggests:

"But over Christmas periods for example, we want our customers not to be ordering long life products. We want them to be using the stocks as they turn. We regularly as a matter of process issue an instruction, "we are in FIFO situation, please don't order for stock, if you do order for stock then give us a justification and a reason." INT - Hospital Services Manager BC 1-3 Case 1-3

Hospitals in Context-2 also demonstrate their reluctance to simplify when they confirm errors, e.g. incorrect labels on blood products, with the blood centre. Further, during the fasting month of Ramadhan, high tempo conditions persist as Muslims, including most of Indonesians, do not eat and drink from sunrise to sunset and many people are reluctant to donate blood for faith or health reasons. It is therefore difficult to maintain blood availability across the BSC. Blood centres employ checks and balances to ensure blood stocks, asking hospitals to confirm blood usage to avoid wastage. A Midwife at the SD Hospital emphasises:

"But here is the fact [when it comes to order during fasting month, the blood centre will question], "is it really going to be used? Because this is fasting month"." INT - Midwife SD Hospital Case 2-2

In emergency conditions, hospitals in Context-1 employ redundancy when they share urgent order information by telephone in addition to using the Online Blood Ordering System (OBOS), to ensure the immediate attention of blood centre staff. Emergency situations often occur at night, when the number of staff in the blood centre is reduced and staff have responsibilities in addition to order processing. As an Operational Manager Transfusion and Haematology at the NG Hospital describes:

"And then in the emergency situations, we still use OBOS, but we also follow that up with the phone call to NHSBT [...]. We ring them directly because you know we are aware certainly overnight, there might only be one person, one member of staff. They are maybe in a fridge somewhere stocking up. They may not notice the order coming through on OBOS. So we always follow up for emergencies with a phone call." INT - Operational Manager Transfusion and Haematology NG Hospital Case 1-2 


\section{Sensitivity to operations (SO)}

We find that BSC actors demonstrate their sensitivity to operations through the IOIS processes of transparency, regular and real time interactions and ongoing operational adjustments, across all cases in Context-1 and Case 2-1 in Context-2.

Hospitals in Context-1 show transparency when they share daily blood stock levels, usage, and wastage data with blood centres via their data management system, VANESA. This information is shared back with the hospitals as monthly trend reports, allowing hospitals to benchmark their operations against BSC system performance at the local, regional, and national levels, potentially improving blood safety and availability.

In addition to regular and real time interactions, the BSC actors in Context-1 also implement ongoing operational adjustments to prevent errors from cumulating. For example, when hospitals realise that the wastage of a particular blood group is increasing, they act to adjust (reduce) their stock levels and therefore their orders to the blood centre to reduce wastage. Similarly, when hospitals realise that they require additional stocks to fulfil patient demand, they share the information with the blood centre. As a Biomedical Scientist at the SM Hospital suggests:

“[...] our thing, recently has been platelets, this is obviously because they've got a short shelf life anyway. We did go through a period where we were using a lot of ad hoc deliveries so we were feeding that back and obviously NHSBT are aware that we are using a lot of ad hoc deliveries. And through discussion with our customer service manager we actually decided to hold stock of platelets. And now we've adjusted that to hold the stock, two stock platelets over the weekend. So that's something we've been able to put in place, feeding back and forth between ourselves and NHSBT." INT - Lead Biomedical Scientist SM Hospital Case 1-2

In Case 2-1, transparency is demonstrated when the blood centre and its associated hospitals share temperature control information and collectively monitor blood quality conformance. Regular interactions are maintained when the blood centre staff visit hospitals to carry out monthly process audits and to disseminate blood management updates. The blood centre provides hospitals access to live information on blood stock levels on its website and social media, demonstrating real time interactions. Finally, hospitals make ongoing operational adjustments by immediately sharing order information responding to changes in their stock levels. As a Laboratory Manager at the PMU Hospital describes:

"I always monitor blood stock every day. So for example, we have 10 stock in one day. Tomorrow morning when we come, we will check how many stocks we need. We then immediately call the 
blood centre, that very morning we order again. We don't want the delay." INT - Laboratory Manager PMU Hospital Case 2-1

\section{Commitment to resilience $(C R)$}

We find that BSC actors demonstrate their commitment to resilience through the IOIS behaviours of readiness and responsiveness in high tempo and emergency conditions, in all cases.

Hospitals and blood centres in Context-1 demonstrate both readiness and responsiveness when they follow known procedures efficiently in high tempo conditions. For example, when a patient suffers a severe reaction to a transfusion, the hospital will immediately share information with the blood centre to confirm the actions required or when a blood centre identifies a problem with blood units which have already been delivered to hospitals, a product recall instruction will be shared with the hospitals, requiring them to immediately take the product out of stock and circulation. Responsive information sharing is vital to ensure changes to operations can be actioned efficiently, ensuring blood safety for patients, particularly if the recalled product has already been transfused. Similarly, in Context-2, hospitals show responsiveness by contacting the blood centre immediately when a severe reaction to transfusion is identified or in response to stock-outs.

In emergency conditions, such as a natural disaster, for example a flood in a manufacturing centre in Context-1, information is immediately shared between NHSBT and the hospitals to ensure all parties are aware of the situation and operations are responsively adjusted to maintain blood safety and availability across the BSC. As the Transfusion Operations Manager at BNH hospital reports:

"[...] We were involved obviously with Filton [flood] and then they kept us up to speed. But the local distribution centres were able to supply our components and we were informed [...]. We'd also be communicating with the NHSBT to say that "all of the deliveries and the components will be going to one site". And we may well be looking at shipping components temporarily back to them for storage and then bringing them back. [...] It tends to be phone because those sort of circumstances we'll tend to need an immediate response or rapid response and I think relying on email is not conducive for speedy action." INT - Transfusion Operations Manager BNH Hospital Case 1-3

In the event of a major haemorrhage, the patient bleeds heavily and will often use up all of the blood stock available in a hospital. In this situation in both Contexts, an emergency (blue light) order is shared with the blood centre. This will allow blood stocks to be replenished as quickly as possible. As the Blood Bank Manager in AK Hospital describes: 
"So there was a case of an obstetric patient that was heavily bleeding and requires 6 packs of blood. I think it was $O$ [pos] blood group so it was easier to fulfil. But then several hours later, this patient requires more. [...] It was stockout because the need was higher than [expected]. We then immediately placed an emergency order by phoning the blood centre. We could then provide the blood." INT - Blood Bank Manager AK Hospital Case 2-2

\section{Deference to expertise (DE)}

Our findings show that the BSC actors demonstrate deference to expertise through collective and expertise-based decision making in normal and high tempo conditions only in case 1-2 of Context-1. For example, in normal conditions collective decision making is identified when BSC actors share information to collectively determine ideal stock levels. Expertise-based decision making is shown when the blood centre provides advice on appropriate blood use whilst leaving the final decision to the hospital clinician. As the Hospital Services Manager at the BC 1-2 Blood Centre suggests:

"[...] we wouldn't make that judgement call, it would be with the clinician. So we wouldn't say to the hospital that you need this instead of this. But we might advise." INT - Hospital Services Manager BC 1-2 Case 1-2

In high tempo conditions, collective decision making is demonstrated when BSC actors in Case 1-2 collectively review their stock levels and suggest actions in response to a national blood shortage. In the case of a serious reaction to transfusion, expertise based decision making is shown when the blood centre defers the product recall decision to the consultant haematologist, who will then collectively review the reaction with the hospitals and decide whether the units need to be recalled. As a Transfusion Practitioner at the WP Hospital describes:

"So if we have a serious reaction, the protocol is that we would contact NHSBT. They would give us the name of the consultant haematologist on call for NHSBT and they review that reaction with us. And then they will make the decision as to whether that unit needs to be recalled or not. If they want it recalled, we obviously quarantine that unit. And then they will send a box, we pack it and everything, it goes back to NHSBT, and then they will culture the units and then NHSBT then send us the report back on their findings. [...] So it's a telephone conversation. And occasionally they might ask for additional information via email." INT - Transfusion Practitioner WP Hospital Case 1-2 


\section{Changes in blood safety and availability (BSA)}

Our analysis suggests that the demonstration of CM principles can explain the underlying mechanisms that are responsible for the changes in BSA in the Cases of both contexts, under a range of operational conditions. We categorise the changes into five groups:

1. Realised improvement in BSA - changes that reflect actual improvements in BSA compared to before IOIS. For example, BSC actors demonstrate their sensitivity to operations when real time blood stock level information is shared between a blood centre and its associated hospital under the vendor-managed inventory (VMI) programme. This results in more effective replenishment of the hospital's blood stock, and better blood availability across the BSC, compared to before VMI.

2. Potential improvement in BSA - changes that could potentially lead to an improvement in BSA after IOIS. For example, BSC actors demonstrate their preoccupation with failure when they share blood safety incident reports across the BSC. Awareness of these lessons learnt can lead hospitals to change their practices, potentially preventing similar incidents happening in the future.

3. Assurance of BSA - the prevention of unwanted changes that could potentially lead to worse BSA. For example, our data suggests that BSC actors demonstrate preoccupation with failure when a blood centre questions out of the ordinary orders from their hospital to ensure that the order is appropriate and the hospital is using the ordered blood safely.

4. Adjustment of operations for BSA - making changes (which can be temporal in nature) to maintain BSA after IOIS. For example, BSC actors demonstrate their sensitivity to operations and commitment to resilience when hospitals are notified of a shortage in a critical blood group such as $\mathrm{O}$ negative. Hospitals will then adjust their practices, to reduce usage of the critical group to maintain the availability across the BSC.

5. Potential adjustment of operations for BSA - potential changes to operations to maintain BSA after IOIS. For example, showing sensitivity to operations, a hospital might inform its associated blood centre of changes in medical practice, which will subsequently increase the demand for a particular blood group. This awareness allows the blood centre to adjust their services to meet demand and maintain blood availability across the BSC.

Table 3 presents the relationship between these changes and the CM principles, for each context across the range of operational conditions investigated, normal $(\mathrm{N})$, high tempo $(\mathrm{HT})$, and emergency (E). 
Table 3: CM principles and changes in BSA across cases

\begin{tabular}{|c|c|c|c|c|c|c|c|c|c|c|c|c|c|c|c|c|}
\hline \multirow[t]{2}{*}{$\begin{array}{c}\text { Case } \\
\text { study } \\
\text { contexts }\end{array}$} & \multirow[t]{2}{*}{ CM principles } & \multicolumn{3}{|c|}{$\begin{array}{l}\text { Realised } \\
\text { improvement } \\
\text { in BSA }\end{array}$} & \multicolumn{3}{|c|}{$\begin{array}{l}\text { Potential } \\
\text { improvement } \\
\text { in BSA }\end{array}$} & \multicolumn{3}{|c|}{$\begin{array}{l}\text { Assurance } \\
\text { of BSA }\end{array}$} & \multicolumn{3}{|c|}{$\begin{array}{l}\text { Adjustment of } \\
\text { operations for } \\
\text { BSA }\end{array}$} & \multicolumn{3}{|c|}{$\begin{array}{l}\text { Potential } \\
\text { adjustment of } \\
\text { operations for } \\
\text { BSA }\end{array}$} \\
\hline & & $\mathrm{N}$ & HT & $\mathrm{E}$ & $\mathrm{N}$ & $\mathrm{HT}$ & $E$ & $\mathrm{~N}$ & HT & $E$ & $\mathrm{~N}$ & $\mathrm{HT}$ & $E$ & $\mathrm{~N}$ & HT & $E$ \\
\hline \multirow{5}{*}{ Context-1 } & $\begin{array}{l}\text { Preoccupation } \\
\text { with failure }\end{array}$ & $\sqrt{ }$ & - & - & $\sqrt{ }$ & $\sqrt{ }$ & - & $\sqrt{ }$ & $\sqrt{ }$ & - & - & $\sqrt{ }$ & - & $\sqrt{ }$ & $\sqrt{ }$ & - \\
\hline & $\begin{array}{l}\text { Reluctance to } \\
\text { simplify }\end{array}$ & $\sqrt{ }$ & - & - & $\sqrt{ }$ & $\sqrt{ }$ & $\sqrt{ }$ & $\sqrt{ }$ & $\sqrt{ }$ & $\sqrt{ }$ & $\sqrt{ }$ & - & $\sqrt{ }$ & $\sqrt{ }$ & $\sqrt{ }$ & $\sqrt{ }$ \\
\hline & $\begin{array}{l}\text { Sensitivity to } \\
\text { operations }\end{array}$ & $\sqrt{ }$ & - & - & $\sqrt{ }$ & - & - & $\sqrt{ }$ & - & - & $\sqrt{ }$ & - & - & $\sqrt{ }$ & - & - \\
\hline & $\begin{array}{l}\text { Commitment to } \\
\text { resilience }\end{array}$ & - & $\sqrt{ }$ & - & - & $\sqrt{ }$ & - & - & $\sqrt{ }$ & $\sqrt{ }$ & - & $\sqrt{ }$ & $\sqrt{ }$ & - & $\sqrt{ }$ & $\sqrt{ }$ \\
\hline & $\begin{array}{l}\text { Deference to } \\
\text { expertise }\end{array}$ & $\sqrt{ }$ & - & - & - & - & - & $\sqrt{ }$ & $\sqrt{ }$ & - & - & - & - & - & $\sqrt{ }$ & - \\
\hline \multirow{3}{*}{ Context-2 } & $\begin{array}{l}\text { Reluctance to } \\
\text { simplify }\end{array}$ & - & - & - & $\sqrt{ }$ & - & - & $\sqrt{ }$ & - & - & - & - & - & $\sqrt{ }$ & - & - \\
\hline & $\begin{array}{l}\text { Sensitivity to } \\
\text { operations }\end{array}$ & - & - & - & $\sqrt{ }$ & - & - & $\sqrt{ }$ & - & - & $\sqrt{ }$ & - & - & $\sqrt{ }$ & - & - \\
\hline & $\begin{array}{l}\text { Commitment to } \\
\text { resilience }\end{array}$ & - & - & - & - & - & - & - & $\sqrt{ }$ & - & - & - & $\sqrt{ }$ & - & $\sqrt{ }$ & $\sqrt{ }$ \\
\hline
\end{tabular}

\section{Discussion}

Our analysis, summarised in Table 3, shows that the BSC actors in the cases in Context-1 are more collectively mindful, demonstrating more $\mathrm{CM}$ principles across a wider range of operational conditions compared to the BSC actors in the cases in Context-2. Further, the greater number of $\mathrm{CM}$ principles demonstrated in the cases of Context-1 result in more positive changes in BSA compared to those found in the cases of Context-2. These results indicate that demonstrating CM through IOIS in the cases of Context-1 not only assures BSA in response to dynamic changes in the environment, but also improves BSA performance across the BSC. This pattern is not widely observed in cases of Context-2, which focusses on adjustment of operations to achieve BSA. This leads to our first proposition:

P1: The demonstration of more collective mindfulness principles leads to a greater number of positive changes in blood safety and availability in the supply chain.

Our research contributes to the elaboration of CM theory via vertical and horizontal contrasting (Fisher and Aguinis, 2017). Applying vertical contrasting we use a theory developed at one level of analysis to explain a phenomenon at another level of analysis, proposing an elaborated understanding of $\mathrm{CM}$ that goes beyond the perspective of a single organisation 
(see Lekka, 2011; Weick and Sutcliffe, 2015, 2007; Weick et al., 1999). Our results reveal that, for our cases, the demonstrations of CM principles at the supply chain level (Figure 2) are not entirely consistent with the original theory (Figure 1). This corroborates Weick et al. (1999) who predict the complexity and challenges faced when CM theory is adopted in the interorganisational context. They suggest that "reliability will be an emerging concern as organizations increasingly participate in interorganizational networks because interorganizational coordination is so difficult to achieve and because the system becomes more complex and harder to comprehend" (Weick et al., 1999:57). This leads us to our second proposition:

P2: Collective mindfulness principles are demonstrated differently at the supply chain compared to the organisational level.

Our vertical contrasting also finds that some CM principles are demonstrated more dynamically in the BSC context (Figure 2), being observed in conditions beyond those prescribed in the original theory (Figure 1). For example, CM theory posits that, to maintain high reliability performance in an organisation, the principles of preoccupation with failure (PF), reluctance to simplify (RS), and sensitivity to operations (SO) should be demonstrated before disruptive events occur, as they represent proactive approaches to error detection. Whereas, commitment to resilience (CR) and deference to expertise (DE) should be demonstrated to contain unexpected events once they have happened (see Weick and Sutcliffe, 2015, 2007; Weick et al., 1999). Our research, however, reveals that in our cases PF is demonstrated not only in normal, but also in high tempo conditions. Similarly, we find that the principle of RS is demonstrated not only in normal, but also in high tempo and emergency conditions. This indicates that, when facing disruptions, BSC actors are not only responsive, immediately resolving blood safety and availability (BSA) problems by sharing information, but they are simultaneously focusing on the future reliability of the system and attempting to prevent further problems from emerging that could potentially affect BSA. In doing so, they are demonstrating a process mindset towards reliability, being mindful of the events occurring now and in the future rather than relying on absolute statistical values. This leads to our third proposition:

P3: Collective mindfulness principles are demonstrated more dynamically in the supply chain level compared to the organisational level i.e. more principles are demonstrated in more operational conditions.

In addition, whilst we find examples of the demonstration of DE in normal and high tempo conditions, we find that in general it is difficult to identify across the investigated cases. CM theory in the organisational context posits that DE is about demonstrating collective rather 
than authoritative (top-down) decision making, sharing information regardless of hierarchical rank, and allowing decision making to migrate, along with problems, to people with relevant expertise (Weick and Sutcliffe, 2007; Weick et al., 1999). However, organisational hierarchy is less applicable in the supply chain context, where actors have more autonomy and clarity of responsibility and roles is more important for inter-organisational information sharing (IOIS) and therefore decision making (see Yang and Maxwell, 2011). Our findings suggest that blood centres and their associated hospitals have equal power, being bound by the service level agreement not hierarchy. In addition, both blood centres and hospitals have their own blood management expertise, therefore, migration of decision making beyond supply and demand issues is unnecessary. As a Chief Biomedical Scientist the Transfusion Manager at the W Hospital emphasises:

I think we do cover the blood safety quality regulations, vein to vein traceability and safety. [...] so from NHS[BT] from vein of donor all the way through to delivery to me, NHSBT are responsible for and services delivered to me until the fate of the unit, be it transfused or wasted, that's my responsibility. [...] And I think between the two organisations you know they've got clear demarcation lines on what they're responsible for and likewise we've got our clear embarkation lines and I don't think there's any mix up of where their liability stops and where ours starts and finishes. I think it's quite clear and I think communication works quite well. I don't think we've got any issues or had any issues. [...] they look after their information and we look after ours. INT - Chief Biomedical Scientist the Transfusion Manager W Hospital Case 1-1

Using horizontal contrasting, we examine the application of the theory in contexts different to the original setting (Fisher and Aguinis, 2017). We offer an additional insight on the application of CM theory beyond typical high hazard organisations (e.g. nuclear power plants, aircraft carriers, air traffic controls) in which the theory was originally developed (see Weick et al., 1999). Our findings build on previous research which has demonstrated the positive impacts of CM in healthcare operations (e.g. Vogus and Sutcliffe, 2007a, b; Vogus et al., 2010). Governmental approaches to healthcare delivery differ across the world with four major approaches being observed (WHO, 2020; Dobrzykowski, 2019). The healthcare funding model adopted in a country has a significant impact on how the healthcare supply chain operates, in particular how it is structured and regulated. By choosing contrasting contexts for our cases in countries with radically different healthcare delivery systems, our research explores how structure and regulation impact on how SC actors demonstrate CM principles and the influence this has on the reliability of the SC. This has not been found in the extant literature (see Pirabán et al., 2019; Sawyerr and Harrison, 2020). 
Despite some common mechanisms found in both contexts which explain how CM influences BSA (Figure 2), this research suggests that the BSC actors in the cases in the more centralised and tightly regulated setting demonstrate more CM principles and thus are collectively more mindful than those in the cases in the more decentralised and loosely regulated setting. Whilst our research cannot answer why this happens, this research corroborates the extant literature which argues that some degree of centralisation is required to be collectively mindful and to improve the reliability of operations (Rijpma, 1997 as cited in Weick et al., 1999). On the other hand, "excess decentralization can weaken the comprehension of wider threats and the capacity to coordinate responses", therefore creating a lower collective mindfulness environment (see Weick and Sutcliffe, 2007:150). This leads to our fourth proposition:

P4: The structure of the supply chain has a key influence on how collective mindfulness principles are demonstrated by supply chain actors and hence how blood safety and availability can be improved.

Interestingly, contrary to the findings of earlier studies (see La Porte and Thomas, 1995; Lekka, 2011; Butler and Gray, 2006; Kutsch et al., 2013; Sitkin et al., 1994; Weick et al., 1999), our research suggests that tighter regulation supports rather than hinders the wider demonstration of CM principles in the BSC. Whilst further research is required to prove this proposition at the supply chain level, the extant literature has addressed this phenomenon at the organisational level. Studies suggest that organisations are increasingly reliant on a mix of routine-based and mindfulness-based reliability (Andersen and Hanstad, 2013; Butler and Gray 2006; Turner et al., 2016). Whilst being compliant with rules and procedures, organisations can "infuse" CM elements not only under normal conditions, but also during times of incidents and major crises (Turner et al., 2016). In this regard, tight regulation can be simultaneously coupled with the demonstration of CM to create a robust system leading to reliable performance (see La Porte and Thomas, 1995). This leads to our final proposition:

P5: At the supply chain level, tight regulation supports the demonstration of collective mindfulness principles and therefore improvement in blood safety and availability. 


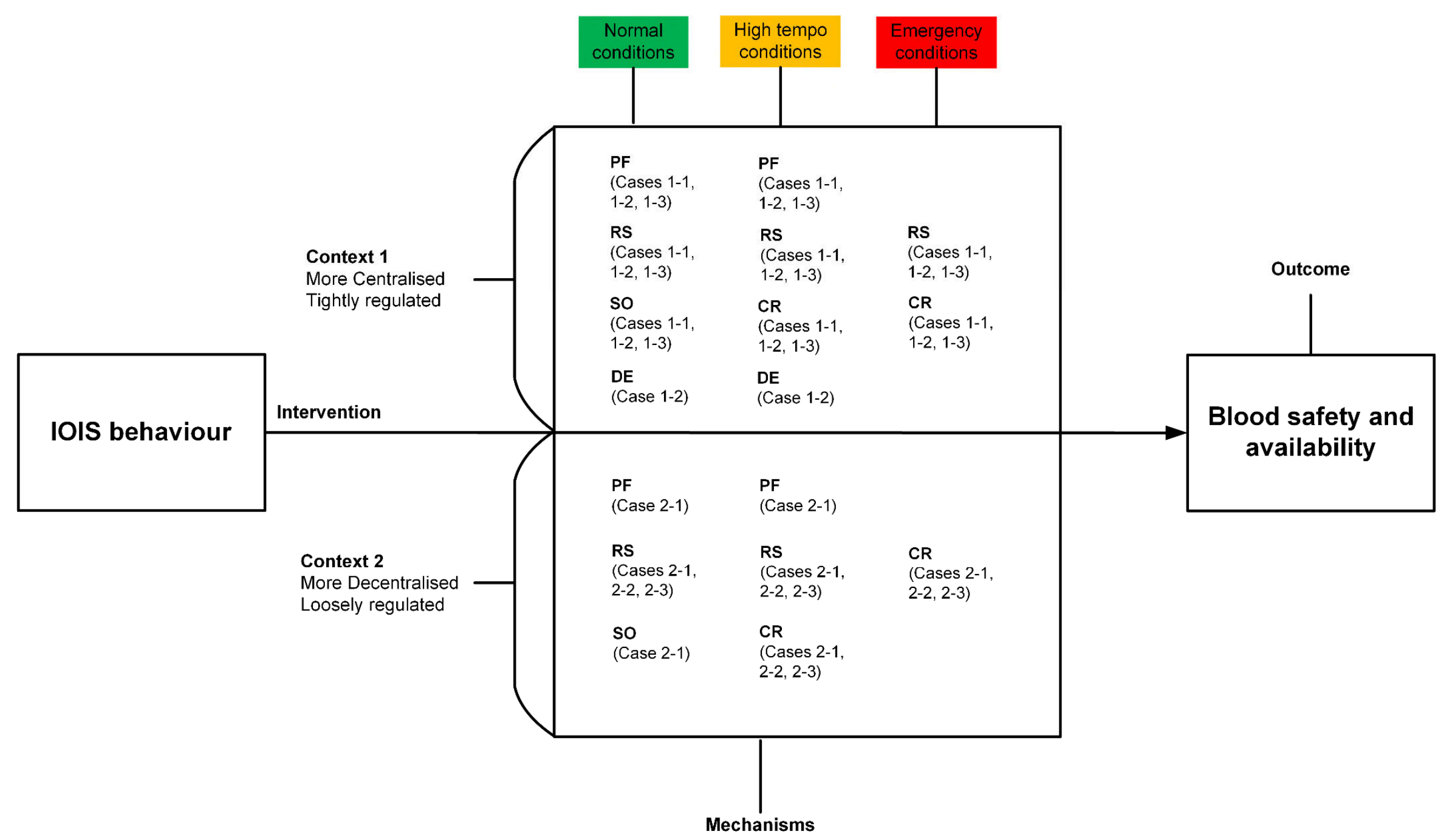

Figure 2: Refined theoretical framework of collective mindfulness in the blood supply chain 


\section{Conclusions}

This research aims to investigate how BSC actors demonstrate CM principles through their IOIS behaviour and how these demonstrations lead to BSA improvements in different operational contexts and conditions. Our results find that CM principles are demonstrated by BSC actors in all cases and operational conditions, but that more CM principles are demonstrated under more operational conditions leading to more improvements in BSA in the cases in the more centralised and tightly regulated context. We therefore contribute a vertical elaboration of $\mathrm{CM}$ theory beyond the organisational to the supply chain context, proposing that at this level of analysis more CM principles are demonstrated more dynamically than is suggested by the organisational level theory. In addition, we propose a horizontal elaboration of $\mathrm{CM}$ theory, presenting a theoretical examination of a context where little theory has been developed. We find that in our cases, studying the CM behaviours of the BSC actors provides a process driven behaviourally related model for improving reliability in a context which has traditionally been driven by quantitative analysis. In our cases we find that the demonstration of more CM principles leads more positive changes in BSA and that structure and regulation are important contributing factors. We summarise our contribution by offering five propositions to guide future work in the application of $\mathrm{CM}$ as a powerful tool for developing process reliability approaches in the blood supply chain context and beyond.

Our research is limited to studying CM principles and their impacts on BSA across cases in different operational contexts. Our propositions offer a potential vehicle for understanding how CM principles can be used to develop process reliability based mechanisms in other supply chain contexts. Understanding how and why the contexts affect the results is beyond our scope and future research could focus on this interesting area. Our limitation also stems from the use of $\mathrm{CM}$ theory developed from the Western perspective of individual mindfulness. Other mindfulness perspectives involving meditation as commonly found in the Eastern practices of mindfulness are not considered in this study. Furthermore, although the multiple case study investigated in this research offers stronger and more compelling empirical insights compared to a single case study, it is the nature of case study research that the generalisability of the findings is limited to theoretical or analytical, rather than statistical generalisation (Yin, 2014). As such, the findings of this research do not represent the general populations to which the investigated cases belong; instead, these findings may be applied with care to explain similar phenomena in similar study contexts, such as perishable product and/or healthcare SCs. Large scale surveys could be conducted in the future to generalise our findings and to test the propositions. 


\section{References}

Aggarwal, S. and Srivastava, M.K. (2016), "Towards a grounded view of collaboration in Indian agri-food supply chains: a qualitative investigation”, British Food Journal, Vol. 118 No. 5, pp. 1085-1106.

Andersen, S. and Hanstad, D.V. (2013), "Knowledge development and transfer in a mindful project-organization", International Journal of Managing Projects in Business, Vol. 6 No. 2, pp. 236-250.

Beliën, J. and Forcé, H. (2012), "Supply chain management of blood products: a literature review", European Journal of Operations Research, Vol. 217, pp. 1-16.

Bourgeois, L.J. and Eisenhardt, K.M. (1988), "Strategic decision processes in high velocity environments: four cases in the microcomputer industry", Management Science, Vol. 34 No. 7, pp. 816-835.

Butler, B.S. and Gray, P.H. (2006), "Reliability, mindfulness, and information systems", MIS Quarterly, Vol. 30 No. 2, pp. 211-224.

Curtis, A.M., Dennis, A.R. and McNamara, K.O. (2017), "From monologue to dialogue: performative objects to promote collective mindfulness in computer-mediated team discussions", MIS Quarterly, Vol. 41 No. 2, pp. 559-581.

Diabat, A., Jabbarzadeh, A. and Khosrojerdi, A. (2019), "A perishable product supply chain network design problem with reliability and disruption considerations", International Journal of Production Economics, Vol. 212, pp. 125-138.

Dobrzykowski, D. (2019), “Understanding the downstream healthcare supply chain: unpacking regulatory and industry characteristics", Journal of Supply Chain Management, Vol. 55 No. 2, pp. 26-46.

Eisenhardt, K.M. (1989a), "Building theories from case study research", The Academy of Management Review, Vol. 14 No. 4, pp. 532-550.

Eisenhardt, K.M. (1989b), "Making fast strategic decisions in high-velocity environments", Academy of Management Journal, Vol. 32, pp. 543-576.

Fisher, G. and Aguinis, H. (2017), "Using theory elaboration to make theoretical advancements", Organizational Research Methods, Vol. 20 No. 3, pp. 438-464.

Goswami, S., Teo, H.H. and Chan, H.C. (2009), "Decision-maker mindfulness in IT adoption: the role of informed culture and individual personality", in Proceedings of the 30th international conference on information systems (ICIS), 2009, Phoenix.

Halligan, M. and Zecevic, A. (2011), "Safety culture in healthcare: a review of concepts, dimensions, measures and progress", BMJ Quality \& Safety, Vol. 20, pp. 338-343. 
Harman, G.H. (1965), "The inference to the best explanation", Philosophical Review, Vol. 74 No. 1 , pp. 88-95.

Hopkins, A. (2007), "The problem of defining high reliability organisations", working paper

51, The Australian National University, Canberra, January.

Jick, T.D. (1979), "Mixing qualitative and quantitative methods: triangulation in action", Administrative Science Quarterly, Vol. 24, pp. 602-611.

Kembro, J. and Näslund, D. (2014), "Information sharing in supply chains, myth or reality? A critical analysis of empirical literature", International Journal of Physical Distribution and Logistics Management, Vol. 44 No. 3, pp. 179-200.

Kembro, J., Selviaridis, K. and Näslund, D. (2014), "Theoretical perspectives on information sharing in supply chains: a systematic literature review and conceptual framework", Supply Chain Management: An International Journal, Vol. 19 No. 5/6, pp. 609-625.

Ketokivi, M. (2006), "Elaborating the contingency theory of organizations: the case of manufacturing flexibility strategies", Production and Operations Management, Vol. 15 No. 2, pp. 215-228.

Ketokivi, M. and Choi, T. (2014), "Renaissance of case research as a scientific method", Journal of Operations Management, Vol. 32 No. 5, pp. 232-240.

King, A. (2008), "In Vivo coding”, in Given, L.M. (Ed.), The SAGE Encyclopedia of Qualitative Research Methods, SAGE Publications, Inc., Thousand Oaks, pp. 473-474.

King, N. (2012), "Doing template analysis", in Symon, G. and Cassell, C. (Eds.), Qualitative Organizational Research: Core Methods and Current Challenges, SAGE Publications Ltd., London, pp. 426-450.

Kirkman, R.A. (1963), "Failure concepts in reliability theory", IEEE Transactions on Reliability, December.

Kudesia, R.S. (2019), "Mindfulness as metacognitive practice", Academy of Management Review, Vol. 44 No. 2, pp. 405-423.

Kutsch, E., Denyer, D., Hall, M. and Lee-Kelley, E. (2013), "Does risk matter? disengagement from risk management practices in information systems projects", European Journal of Information Systems, Vol. 22 No. 6, pp. 637-649.

Kydd, C. T. (1989), "Understanding the Information Content in MIS Management Tools," MIS Quarterly, Vol. 13 No. 3, pp. 279-290.

Langer, E.J. (2000), "Mindful learning", Current Directions in Psychological Science, Vol. 9 No. 6 , pp. 220-223. 
La Porte, T.R. and Thomas, C.W. (1995), "Regulatory compliance and the ethos of quality enhancement: surprises in nuclear power plant operations", Journal of Public Administration Research and Theory, January 1995.

Lekka, C. (2011), "High reliability organisations: a review of the literature", Research Report RR899, prepared for the Health and Safety Executive UK, available at http://www.hse.gov.uk/research/rrpdf/rr899.pdf (accessed 5 June 2018).

Li, X. and Wang, Q. (2007), "Coordination mechanisms of supply chain systems", European Journal of Operational Research, Vol. 179, pp. 1-16.

Lusiantoro, L., Yates, N., Mena, C. and Varga, L. (2018), "A refined framework of information sharing in perishable product supply chains", International Journal of Physical Distribution and Logistics Management, Vol. 48 No. 3, pp. 254-283.

Martin, J.A. and Eisenhardt, K.M. (2010), "Rewiring: cross-business-unit collaborations in multibusiness organizations", Academy of Management Journal, Vol. 53 No. 2, pp. 265301.

Merton, R.K. (1957), "Social Theory and Social Structure", Free Press, Glencoe, Illinois Ministry of Health Republic of Indonesia (2018), "RS online", available at: http://sirs.yankes.kemkes.go.id/rsonline/report/ (accessed 2 October 2018).

Ministry of Health Republic of Indonesia (2017), "Pelayanan darah di Indonesia", InfoDATIN, available at: http://www.depkes.go.id/folder/view/01/structure-publikasi-pusdatin-infodatin.html (accessed 5 June 2018).

Mohr, J. and Nevin, J.R. (1990), "Communication strategies in marketing channels: a theoretical perspective", Journal of Marketing, October.

Morgeson, F.P. and Hofmann, D.A. (1999), "The structure of collective constructs: implications for multilevel research and theory development", Academy of Management Review, Vol. 24, pp. 249-265.

Pagell, M. and Krause, D.R. (1999), "A multiple-method study of environmental uncertainty and manufacturing flexibility", Journal of Operations Management, Vol. 17, pp. 307-325.

Pirabán, A., Guerrero, W. J. and Labadie, N. (2019), "Survey on blood supply chain management: models and methods", Computers and Operations Research, Vol. 112, pp. $1-23$.

Rahmani, D. (2019), "Designing a robust and dynamic network for the emergency blood supply chain with the risk of disruptions", Annals of Operations Research, Vol. 283, pp. 613-641. 
Rijpma, J.A. (1997) as cited in Weick, K.E., Sutcliffe, K.M. and Obstfeld, D. (1999),

"Organizing for high reliability: processes of collective mindfulness", in Boin, A. (Ed.),

Crisis Management (Vol. 3), SAGE Publications Ltd., London, pp. 81-123.

Roberts, K. (1993), "Cultural characteristics of reliability enhancing organisations", Journal of Managerial Issues, Vol. 5 No. 2, pp. 165-181.

Roberts, K.H. (1990), "Some characteristics of one type of high reliability organization", Organization Science, Vol. 1 No. 2, pp. 160-76.

Rochlin, G.I. (1993), "Defining "high reliability” organizations in practice: a taxonomic prologue" in Roberts, K.H. (Ed.), New challenges to understanding organizations. New York: Macmillan, pp. 11-32.

Rothbauer, P.M. (2008), "Triangulation”, in Given, L.M. (Ed.), The SAGE Encyclopedia of Qualitative Research Methods, SAGE Publications, Inc., Thousand Oaks, pp. 893-894.

Samani, M.R.G. and Hosseini-Motlagh, S. (2019), "An enhanced procedure for managing blood supply chain under disruptions and uncertainties", Annals of Operations Research, Vol. 283, pp. 1413-1462.

Sawyerr, E. and Harrison, C. (2020), "Developing resilient supply chains: lessons from highreliability organisations", Supply Chain Management: An International Journal, Vol. 25 No. 1, pp. $77-100$.

SHOT (2016), "Annual SHOT report 2016”, available at: https://www.shotuk.org/wpcontent/uploads/SHOT-Report-2016_web_11th-July.pdf (accessed 9 May 2018).

SHOT (2017), “Annual SHOT report 2017”, https://www.shotuk.org/wpcontent/uploads/myimages/SHOT-Report-2017-WEB-Final-v4-25-9-18.pdf (accessed 6 August 2019).

SHOT (2018), "Annual SHOT report 2018", https://www.shotuk.org/wpcontent/uploads/myimages/SHOT-Report-2018_Web_Version.pdf (accessed 6 August 2019).

Sitkin, S.B., Sutcliffe, K.M. and Schroeder, R.G. (1994), "Distinguishing control from learning in total quality management: a contingency perspective", Academy of Management Review, Vol. 19 No. 3, pp. 537-564.

Souza, M.L.H., da Costa, C.A., Ramos, G.O. and Righi, R.R. (2020), "A survey on decisionmaking based on system reliability in the context of Industry 4.0", Journal of Manufacturing Systems, Vol. 56, pp. 133-156.

Spender, J.C. (1989), Industry Recipes: An Enquiry into the Nature and Sources of Managerial Judgement, Basil Blackwell, Oxford, UK. 
Stanger, S.H.W. (2013), "Vendor managed inventory in the blood supply chain in Germany: evidence from multiple case studies", Strategic Outsourcing: An International Journal, Vol. 6 No. 1, pp. 25-47.

Stanger, S.H.W., Yates, N., Wilding, R. and Cotton, S. (2012), "What drives perishable inventory management performance? Lessons learnt from the UK blood supply chain", Supply Chain Management: An International Journal, Vol. 17 No. 2, pp. 107-123.

Sutcliffe, K.M. (2011), "High reliability organizations (HROs)", Best Practice and Research: Clinical Anaesthesiology, Vol. 25 No. 2, pp. 133-144.

Turnbull, B. (1989), "Logistics in the food and drink industry", Management Services, Vol. 33 No. 2, pp. 6-10.

Turner, B. (1976), "The organizational and interorganizational development of disasters", Administrative Science Quarterly, Vol. 21, pp. 378-397.

Turner, N., Kutsch, E. and Leybourne, S.A. (2016), "Rethinking project reliability using the ambidexterity and mindfulness perspectives", International Journal of Managing Projects in Business, Vol. 9 No. 4, pp. 845-864.

Van Donselaar, K., Woensel, T., Broekmeulen, R. and Fransoo, J. (2006), "Inventory control of perishables in supermarkets", International Journal of Production Economics, Vol. 104 No. 2, p. 462-472.

Vogus, T.J. and Sutcliffe, K.M. (2012), "Organizational mindfulness and mindful organizing: a reconciliation and path forward", Academy of Management Learning \& Education, Vol. 11 No. 4 , pp. 722-735.

Vogus, T.J. and Sutcliffe, K.M. (2007a), "The safety organizing scale”, Medical Care, Vol. 45 No. 1 , pp. $46-54$.

Vogus, T.J. and Sutcliffe, K.M. (2007b), "The impact of safety organizing, trusted leadership, and care pathways on reported medication errors in hospital nursing units", Medical Care, Vol. 45 No. 10 , pp. 997-1002.

Vogus, T.J., Sutcliffe, K.M. and Weick, K.E. (2010), "Doing no harm: enabling, enacting, and elaborating a culture of safety in health care", Academy of Management Perspectives, Vol. 24 No. 4, pp. 60-77.

Voss, C., Tsikriktsis, N. and Frohlich, M. (2002), "Case research in operations management", International Journal of Operations \& Production Management, Vol. 22 No. 2, pp. 195219.

Weick, K.E. and Putnam, T. (2006), "Organizing for mindfulness: eastern wisdom and western knowledge", Journal of Management Inquiry, Vol. 15 No. 3, pp. 275-287. 
Weick, K.E. and Sutcliffe, K.M. (2015), Managing the Unexpected: Sustained Performance in a Complex World, John Wiley \& Sons, Inc., Hoboken, New Jersey.

Weick, K.E. and Sutcliffe, K.M. (2007), Managing the Unexpected: Resilient Performance in an Age of Uncertainty ( $2^{\text {nd }} E d$.), Jossey-Bass, San Francisco.

Weick, K.E., Sutcliffe, K.M. and Obstfeld, D. (1999), "Organizing for high reliability: processes of collective mindfulness", in Boin, A. (Ed.), Crisis Management (Vol. 3), London: SAGE Publications Ltd., pp. 81-123.

WHO (2020), "Blood safety and availability", available at: https://www.who.int/newsroom/fact-sheets/detail/blood-safety-and-availability (accessed 3 June 2021).

WHO (2017), "Global status report on blood safety and availability 2016", Geneva: World Health Organization; 2017. Licence: CC BY-NC-SA 3.0 IGO.

Yang, T.M. and Maxwell, T.A. (2011), "Information-sharing in public organizations: a literature review of interpersonal, intra-organizational and inter-organizational success factors", Government Information Quarterly, Vol. 28 No. 2, pp. 164-175.

Yin, R.K. (2014), Case Study Research: Design and Methods (5 ${ }^{\text {th }}$ Ed.), SAGE Publications, Inc., Thousand Oaks, California.

Yin, R.K. (2003), Case Study Research: Design and Methods (3 ${ }^{\text {rd }}$ Ed.), SAGE, Newbury Park, California.

Zohar, D. and Luria, G. (2003), "Organizational meta-scripts as a source of high reliability: the case of an army armored brigade", Journal of Organizational Behavior, Vol. 24 No. 7 , pp. 837-859. 